\title{
An equivalent posture to squatting is seen in an unoperated adult with tetralogy of Fallot
}

Keywords: Adults with congenital heart disease; cyanosis

Sir,

The advances in paediatric cardiology and cardiac surgery have led to earlier and earlier surgical repair of congenital cardiac malformations. In consequence, the clinical picture of many congenital cardiac malformations has changed, and some signs and symptoms are no longer observed in their typical appearance. Sometimes, however, it is possible to recognise the transformation of an old symptom or sign into a new one, with a new clinical appearance, as we have recently observed in an adult patient with tetralogy of Fallot.

The old sign is squatting, which is the characteristic instinctive knees-to-chest-position assumed after exertion by patients with certain types of cyanotic congenital cardiac malformations, notably tetralogy of Fallot. Squatting was initially brought to prominence by Taussig, ${ }^{1}$ and generally appears at about one year of age, or when the child starts walking. Investigations have shown that the saturations of oxygen, diminished by exercise, can return to the levels prior to exercise more rapidly when the subject adopts a squatting rather than a standing position. ${ }^{2,3}$ This beneficial effect of squatting is probably due to two phenomenons. The first is the exclusion from the circulation of the highly unsaturated blood from the legs, due to the compression of the femoral vessels. The second is the reduction in the degree of right-to-left shunting due to the increase of peripheral vascular resistance, which opposes the right-to-left shunt through the ventricular septal defect, and increases the flow of blood to the lungs. During hypoxic spells, an infant incapable of standing also tries to obtain the same physiological effects of squatting, compressing his abdomen against the shoulder of his caregiver.

What happens in adults? We have recently observed a 40 year-old man with tetralogy of Fallot, who had always refused surgical treatment. His clinical condition progressively worsened during his life, with increasing cyanosis, dyspnoea on exertion, and severe limitation in his physical activity. This man previously loved working in the countryside, and would not abandon this hobby even if it caused him severe fatigue and cyanosis. When he was exhausted, he would return home on his tractor, and press his abdomen against the top of a small refrigerator that was in the garage, assuming a position with his legs on one side of the refrigerator and his head on the other. This position permitted him more rapidly to return to his usual state more rapidly. This clinical observation indicates that adults with tetralogy of Fallot use manoeuvres that are equivalent to squatting.

$$
\begin{array}{r}
\text { Nicola Carano and Bertrand Tchana } \\
\text { Department of Pediatrics - Pediatric Cardiology Unit } \\
\text { University of Parma } \\
\text { Parma, Italy }
\end{array}
$$

\section{References}

1. Taussig HB. Congenital Malformations of the Heart. 2nd edition. The Commonwealth Fund, Harvard University Press, Cambridge, 1960 , p. 23.

2. Lurie PR. Postural effects in tetralogy of Fallot. Am J Med 1953; 15: 297-306.

3. Nadas AS, Fyler DC. Pediatric Cardiology. W B Saunders Company, Philadelphia, 1972, p. 308. 